\title{
Treatment of Central Nervous System Complications of Renal Dialysis and Transplantation
}

Samer Dahdaleh, MBBS, BSC, MRCP $P^{1,2, *}$ Paresh Malhotra, MA, BMBCh, PhD, FRCP $P^{1,2}$

\author{
Address \\ ${ }^{1}$ Division of Brain Sciences, Imperial College London, Charing Cross Hospital, \\ Fulham Palace Road, London, W6 8RF, UK \\ ${ }^{*}, 2$ Department of Clinical Neurology, Imperial College Healthcare NHS Trust, \\ London, UK \\ Email: s.dahdaleh@nhs.net
}

Published online: 11 March 2019

(C) The Author(s) 2019. This article is an open access publication

This article is part of the Topical Collection on Neurologic Manifestations of Systemic Disease

Keywords Dialysis - Renal transplant · Renal replacement therapy $\cdot$ Central nervous system complications

\begin{abstract}
Purpose of review Most clinical neurologists will have come across individuals receiving renal replacement therapy who have developed a neurological complication, and neurologists working in, or close to, hospitals with a Renal Unit will be very aware of the range of central nervous system (CNS) complications that may develop in these patients. These can often be difficult to differentiate from disorders relating to renal failure or systemic conditions leading to kidney disease and can in fact arise from the interaction between underlying disease and the side effects of treatment. Patients with renal disease frequently have multiple comorbidities, and it is necessary to take a generally inclusive approach to diagnosis and treatment.

Recent findings Unfortunately, there is a lack of specific high-quality evidence for a number of CNS complications of renal replacement therapy. Here, we review the major CNS complications of dialysis and transplantation, discussing evidence for treatments where available and detailing standard management approaches where evidence is scarce. Summary Given the lack of specific evidence for interventions in the treatment of CNS complications of renal replacement therapy, it is often necessary to take an individualised approach based on comorbidities and applying findings from the general population. In these complex patients, we must stress the importance of collaborative working between neurologists and renal physicians when treating this complex patient group.
\end{abstract}




\section{Introduction}

In 2010, 2.6 million patients were receiving renal replacement therapy (RRT) worldwide; this number is projected to increase to 5.4 million by 2030 [1]. The most recent UK renal registry shows 63,162 adult patients were receiving RRT as of the end of 2016 with 7759 new patients being initiated on RRT during the same year. In the UK, transplant was the most common replacement modality (54\%), followed by haemodialysis (40\%) and peritoneal dialysis (6\%). In 2016, the UK prevalence of patients on RRT was 962 per million population compared to in 2000 when it was 535 per million population [2].
Renal failure is associated with several neurological complications including cerebrovascular disease, cognitive impairment, uraemic encephalopathy, peripheral neuropathy and myopathy [3]. Dialysis only partially corrects the pathophysiological abnormalities that contribute to these, and renal replacement therapy (dialysis and renal transplantation) is associated with other neurological complications. Here, we focus on the treatment of neurological complications that arise in patients receiving renal replacement therapy. These are often multifactorial and may require several problems to be attended to simultaneously.

\section{Treatment of neurological complications of renal replacement therapy}

\section{Cerebrovascular disease}

Ischaemic stroke and chronic kidney disease (CKD) often share traditional risk factors including age, hypertension, high cholesterol and diabetes mellitus. The risk of stroke increases with worsening renal function and increasing albuminuria [4]. Patients with CKD are also at a higher risk of haemorrhage. The combinations of chronic uraemia (which results in platelet dysfunction, including abnormal interaction with the vessel wall), inadequate control of hypertension, intradialytic anticoagulation and use of antiplatelets or anticoagulation increases the risk of haemorrhage [5].

\section{Stroke in dialysis patients}

The incidence of stroke in patients undergoing dialysis is 5-10 times greater than that observed in the general population $[6,7,8 \bullet, 9]$. There is no significant difference in the reported rates of ischaemic stroke between haemodialysis and peritoneal dialysis. However, peritoneal dialysis has a lower risk of haemorrhagic stroke compared to haemodialysis [9], which may be due to the use of anticoagulants during haemodialysis. Mortality in haemodialysis patients with stroke can be approximately three times higher compared to patients with CKD not undergoing haemodialysis [10].

The risk of stroke is increased particularly in the first few weeks of starting dialysis regardless of modality [11]. Stroke tends to occur more commonly during dialysis [12]. Risk factors attributed to haemodialysis include thromboembolism, vascular calcification, haemodynamic instability and amyloidosis.

\section{Stroke in transplant patients}

Transplant leads to an overall improvement in stroke risk when compared to dialysis [13]. Most studies report an increased risk of ischaemic rather than haemorrhagic strokes. The latter is associated with higher mortality [13, 14]. A 
retrospective analysis of 1237 patients from the Imperial renal unit (London) found that $4.5 \%$ of people who received a kidney alone or a simultaneous pancreas and kidney transplant had a stroke after transplantation. Stroke risk factors included age, diabetes mellitus at the time of transplantation, corticosteroid use and receipt of simultaneous pancreas and kidney transplant. Transplant specific factors included immunosuppression, allograft rejection, deceased donor transplantation and long duration of dialysis pre-transplant [15].

Treatment of ischaemic stroke

The complexity of management of ischaemic stroke in chronic kidney disease and renal replacement therapy is that they have higher thrombotic and thromboembolic risk but also higher risk of haemorrhage.

\section{Stroke prevention in patients on dialysis and renal transplant}

Traditionally evidence-based risk factor management for stroke prevention from the general population studies have been applied to patients with all forms of renal impairment. However, some of the evidence suggests that efficacy is not always proven for traditional risk factors, particularly in endstage renal disease (ESRD) patients on dialysis (see below).

There is a strong evidence base for the use of antiplatelet medication in the secondary prevention of stroke in the general population [1618]. However, there are no appropriately sized RCTs that have evaluated the effect of antiplatelets in the prevention of stroke in patients on dialysis or with renal transplant. A Cochrane metaanalysis that included randomised trials of non-dialysis CKD and ESRD patients on RRT found that antiplatelet agents, compared with no treatment or placebo, did not reduce the risk of stroke or mortality but reduced the risk of myocardial infarction. Antiplatelet agents increased the risk of major and minor bleeding [19]. The conclusions that can be drawn from this are limited as the data were mostly derived from post-hoc analyses of trials in the general population.

Observational studies in patients with dialysis have multiple confounding factors including the indication for the antiplatelet medication, selection bias, type and dose of antiplatelet used. In an analysis of over 28,000 haemodialysis patients randomly selected from dialysis outcomes and practice patterns (DOPPS) I and II studies, aspirin was associated with a decreased risk of stroke (relative risk (RR) $0.82 ; p<0.01$ ), but there was an increased risk of myocardial infarction $(\mathrm{RR}, 1.21 ; p=0.01)$ and cardiac events $(\mathrm{RR}, 1.08 ; p<0.01)$ in all patients, with similar results for patients with coronary artery disease. There was no significant difference in the risk of gastrointestinal bleeding [20].

Given the increased bleeding complications and lack of clear demonstrated efficacy of antiplatelets in prevention of stroke in patients on renal replacement therapy, we would recommend an individualised approach, and avoidance of antiplatelet may be reasonable in some patients. 
$\mathrm{AF}$ is a strong risk factor for stroke, and the prevalence of $\mathrm{AF}$ is higher in dialysis patients compared to the general population [21]. However, the benefit of anticoagulation in patients on dialysis is not clear. Novel oral anticoagulants (NOACs) are eliminated by the kidney: $80 \%$ for dabigatran, $50 \%$ for edoxaban, $35 \%$ for rivaroxaban, and $27 \%$ for apixaban. This results in different plasma concentration depending on creatinine clearance; therefore, doses may need adjustment [22 $\bullet$. NOACs are effective and safe in patients with mild to moderate renal impairment (creatinine clearance over 30) when compared with warfarin [23-25]. There is very limited clinical data on NOAC use for patients with a creatinine clearance of $<$ $30 \mathrm{ml} / \mathrm{min}$, and warfarin is of uncertain benefit in patients with ESRD on dialysis $[22 \bullet, 26]$. Thus, the decision to consider anticoagulation in ESRD on dialysis requires a personalised approach depending on risks, benefit and patient preference.

Lipid-lowering therapy

Large randomised controlled trials in patients with normal or mild to moderate CKD have shown benefit for lipid-lowering therapy, especially statins in secondary prevention [27]. There is less clear evidence for the benefit of lipid-lowering therapy in stroke prevention for patients with ESRD on dialysis [27-31]. The rationale supporting the use of these agents in ESRD on dialysis remains unresolved. The Kidney Disease Improving Global Outcomes (KDIGO) guidelines do not recommend initiation of lipid-lowering therapy in patients on dialysis. However they would recommend continuation of therapy in patients established on this prior to dialysis. Treatment should be considered in patients with recent MI or stroke and high LDL levels [32].

The relationship between treatment of dyslipidaemia and reduction in stroke risk in transplant recipients has not been fully established [33]. Dyslipidaemia is a frequent complication after kidney transplantation. Immunosuppressive agents, particularly glucocorticoids, calcineurin inhibitors and rapamycin, have dose-related effects on serum lipid levels. Balancing immunosuppression, the different agents, the risk of rejection and dyslipidaemia is complex. For example, cyclosporine increases the risk of dyslipidaemia compared to tacrolimus; therefore, the latter may be favoured. The KDIGO guidelines recommend treatment with a statin in renal transplant recipients [32]. Some of the immunosuppressive agents such as cyclosporine inhibit the hepatic metabolism of statins and therefore may require lower doses. haemorrhagic stroke in the general population [34]. The evidence for this in the dialysis population is less clear from existing studies [35]. Two metaanalyses of randomised controlled trials that enrolled dialysis patients found that lowering blood pressure (BP) resulted in reduction of 
cardiovascular events. The specific effect on stroke was not presented [36, 37]. Moreover, the optimum target $\mathrm{BP}$ in dialysis population is not clear. In renal transplant patients, the KDIGO guidelines recommend a $\mathrm{BP}<130$ / 80 irrespective of urine albumin excretion based on observational studies. The choice of a BP-lowering agent may depend on time after transplantation, whether calcineurin inhibitors are being used, presence or absence of albuminuria and other comorbidities [38].

\section{Acute reperfusion therapies}

Rapid restoration of cerebral blood flow using reperfusion therapy is the most effective management for salvaging ischemic brain tissue that is not infarcted. The benefit is time-dependant.

Thrombolytic therapy with recombinant tissue plasminogen activator (rt-PA/alteplase) is the standard of care for patients presenting within $4.5 \mathrm{~h}$ of symptom onset following acute ischemic stroke provided there are no contraindications [39, 40]. Alteplase is not contraindicated for use in patients with ESRD and dialysis. However, most of the randomised controlled trials in ischaemic stroke either excluded or did not capture whether patients had ESRD and whether they were on dialysis; therefore, thrombolysis efficacy in these patients is less certain. Post-hoc analysis of the ENCHANTED trial, a multicentre randomised open-label blinded trial comparing low dose $(0.6 \mathrm{mg} / \mathrm{kg})$ to standard dose $(0.9 \mathrm{mg} / \mathrm{kg})$ alteplase, examined the influence of renal impairment on outcome post thrombolysis in acute stroke. Patients with severe renal dysfunction (eGFR $<30 \mathrm{ml} / \mathrm{min}$ ) had an increased risk in mortality but no significant increase in disability or symptomatic intracerebral haemorrhage compared to patients with normal renal function (eGFR $>90 \mathrm{ml} / \mathrm{min}$ ). There was no significant difference between the use of low dose $(0.6 \mathrm{mg} / \mathrm{kg})$ and standard dose $(0.9 \mathrm{mg} / \mathrm{kg})$ alteplase between the two groups. There are several limitations of this study: renal function was derived from a single measurement of creatinine on admission and it was not clear if the patients had acute versus chronic kidney disease or whether they were any patients were on renal dialysis or had a renal transplant. It was also underpowered as only 103 patients had an eGFR $<30 \mathrm{ml} / \mathrm{min}$ out of a total of 3310 patients included in the trial [41•].

The majority of the available data for patients on dialysis are from retrospective observational studies predominantly from haemodialysis cohorts. These have multiple confounding factors including variable dose of alteplase used, different calculation or definition of renal impairment, and different outcome measures. Some studies report an increased risk of symptomatic intracerebral haemorrhage in patients with renal impairment treated with rt-PA $[42,43]$. In the largest registry-based study of US dialysis patients with ischaemic stroke treated with thrombolysis (1008 on haemodialysis and 65 on peritoneal dialysis), there was no increase of intracranial haemorrhage or disability noted, although patients had a 
higher risk of mortality and more prolonged admission [44]. In the absence of definitive data, acute stroke patients on dialysis or with a renal transplant should be treated with thrombolysis if they meet criteria and have no contraindications. The 2018 AHA/ASA guidelines for early management of acute ischaemic stroke recommend the use of alteplase in patients with ESRD on HD with a normal activated partial thromboplastin time (aPTT). Patients with an elevated aPTT may have an increased risk of haemorrhagic complications [16].

Mechanical thrombectomy is indicated in patients with acute ischaemic stroke and large artery occlusion. Several randomised controlled trials have shown that early intra-arterial treatment with second generation mechanical thrombectomy devices is safe and more effective at reducing disability versus standard treatment with intravenous thrombolysis alone when the stroke is caused by a large artery occlusion in the anterior circulation [45-48]. However, to-date trials have included limited information regarding whether any patients have ESRD and are on dialysis. A retrospective analysis of the US Nationwide Inpatient Sample database between 2005 and 2010 compared 1398 dialysis patients presenting with acute ischaemic stroke who were treated with intravenous thrombolytic therapy with 915 patients treated with mechanical thrombectomy. Mechanical thrombectomy was associated with lower in-patient mortality and lower moderate-to-severe disability compared to the intravenous thrombolysis group after adjusting for age, gender and confounding factors [49].

\section{Treatment of cerebral haemorrhage}

Intracerebral haemorrhage in CKD on RRT is most commonly hypertensive in origin and most often affects the basal ganglia, cerebellum or brainstem. There are no specific randomised controlled trials addressing the management of ICH in patients with ESRD on dialysis. Therefore, the management of ICH is similar to the general population, which includes control of blood pressure, urgent reversal of any coagulopathy and consideration of neurosurgical intervention as appropriate [50].

A retrospective study from the Imperial renal unit of 2155 patients on maintenance haemodialysis showed a prevalence of nontraumatic subdural haemorrhage of $0.4 \%$ with an overall annual incidence of 189 per 100,000 patients. This is around 20 times higher than the general population. No association was found with comorbidities such as hypertension, diabetes, or with the use of antiplatelets or anticoagulants [51].

Techniques used to limit systemic bleeding risk include regional anticoagulation and minimal heparin use [52]. Patients who have suffered a recent ICH or are at an increased risk of bleeding can undergo dialysis without anticoagulation (heparin-free dialysis). 
This is a clinical radiographic syndrome that typically develops over hours to days and is characterised by headaches, visual disturbance (visual field defects, hallucinations or cortical blindness), encephalopathy and seizures. Characteristic MRI brain patterns include white matter parieto-occipital changes, but a watershed pattern and superior frontal sulcus pattern are also described. These changes are suggestive of vasogenic oedema [53•]. It is important that this syndrome is recognised early, and the underlying cause is treated to prevent permanent neurological deficits. The diagnosis should be considered in patients with a rapid rise in blood pressure, are on any exacerbating medication for example immunosuppressive medication used in transplant recipients such as calcineurin inhibitors calcineurin inhibitors, or have have systemic autoimmune disorders such as systemic lupus.

There are no randomised controlled trials in the treatment of PRES. Treatment involves treating the underlying cause. This involves lowering blood pressure if elevated, reducing the dose or withdrawing the offending drug, correction of electrolytes (particularly magnesium) and supportive therapy. In case of immunosuppressive agents in transplant, the medication may need to be discontinued and substituted to a different medication [53•]. In the acute setting, anticonvulsants may be required, but withdrawal of antiepileptics can be considered a few months after symptoms and imaging findings have resolved.

Management of seizures in renal dialysis and transplant patients

Several of the CNS complications of renal dialysis and transplant that are discussed in this article can present with seizures (potential causes are summarised in Table 1). The management of acute seizures include investigation and treatment of any underlying cause. The decision to start an anticonvulsant depends on whether the patient is at high risk of seizure recurrence and whether the seizure is provoked or unprovoked. In the context of acute neurological complications, the risk may be increased in the short term, requiring antiepileptic initiation. If the underlying cause resolves, then it is often possible for the antiepileptics to be withdrawn.

The choice and dose of anticonvulsant depends on seizure type, clinical response, pharmacokinetics, interactions with other drugs and any other comorbidities. Renal impairment alters the pharmacokinetics of many antiepileptics. Metabolic acidosis and proteinuria reduce serum albumin and therefore increase free levels of active drug. Decreased glomerular filtration rate and urinary excretion can result in accumulation and increase of levels of some anticonvulsants [54, 55].

Water soluble drugs, such as levetiracetam, have lower protein binding affinity, are predominantly renally excreted and tend to accumulate in renal disease. They are largely removed by dialysis and therefore may require postdialysis dosing. Whilst lipophilic, predominantly protein bound antiepileptics, such as phenytoin, valproate and carbamazepine, tend not to be affected by dialysis [54]. The effect of peritoneal dialysis on antiepileptic levels can be unpredictable.

In patients on dialysis it may be easier to choose protein bound antiepileptics that are cleared through hepatic mechanisms as their levels are less likely to be 


\title{
Table 1. Causes of seizures in renal dialysis and transplant patients
}

\author{
Uraemic encephalopathy \\ Posterior reversible encephalopathy syndrome \\ Hypertensive encephalopathy \\ Dialysis disequilibrium syndrome \\ Stroke (ischaemic and haemorrhagic) \\ Intracranial infections (e.g. meningitis, encephalitis, brain abscess) \\ Hypoglycaemia \\ Hyperglycaemia-nonketotic hyperosmolar coma \\ Electrolyte abnormalities, e.g. hypocalcaemia, hypo- or hypernatraemia \\ Rapid rise in haemoglobin after starting erythropoietin \\ Air embolism \\ Drug toxicity
}

affected by haemodialysis. However, a number of these medications have hepatic enzyme-inducing or inhibiting activity and therefore may interact with other medication. This must be taken into consideration when choosing antiepileptics, particularly in transplant patients on immunosuppressive medication.

Anticonvulsant dose is adjusted depending on seizure control. Drug levels are useful to establish the therapeutic range during remission as a baseline, if patients are refractory to treatment and to guide dose adjustment in the case of changing renal function, interactions with other medications or changes related to dialysis. Measurement of free levels may be required in patients on dialysis. Table 2 contains a list of common antiepileptics and dosing during renal failure and dialysis.

\section{Drug toxicity in patients on dialysis and renal transplant}

Drug toxicity is a common cause of neurological problems in patients treated with renal replacement therapy. Renally excreted drugs (or their active metabolites) can accumulate leading to toxicity. These can be poorly excreted by dialysis particularly if protein bound. These can include medications such as antibiotics, e.g. penicillins and antivirals; e.g. aciclovir, opiates and some antiepileptics. Maintaining therapeutic stable drug levels whilst avoiding side effects is important. Dialysis may increase the elimination of certain drugs, particularly nonprotein bound drugs; these may need further dose supplementation postdialysis. The pharmacokinetics and drug-drug interactions for each drug need to be carefully considered particularly in renal transplant patients on immunosuppressive medication. Neurotoxicity can still occur even during therapeutic drug levels for example immunosuppressive agents (see Table 3).

There are many references to guide dose adjustment in renal impairment and dialysis. For example, the Renal Dosing Database (http://www.globalrph. com/index_renal.htm) provides such dosing guidance. If in doubt, advice from a specialist renal pharmacist is strongly recommended [3]. 


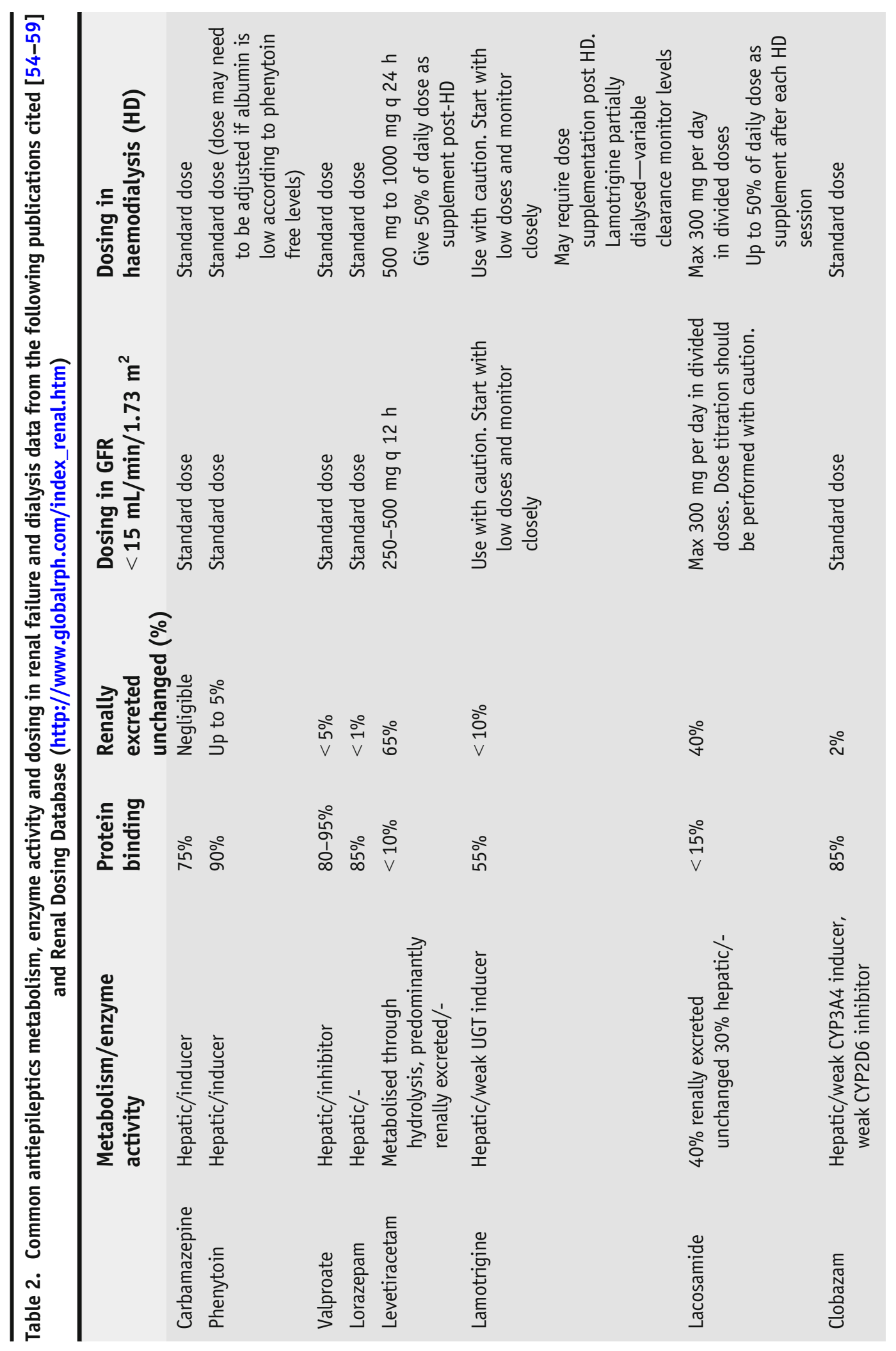




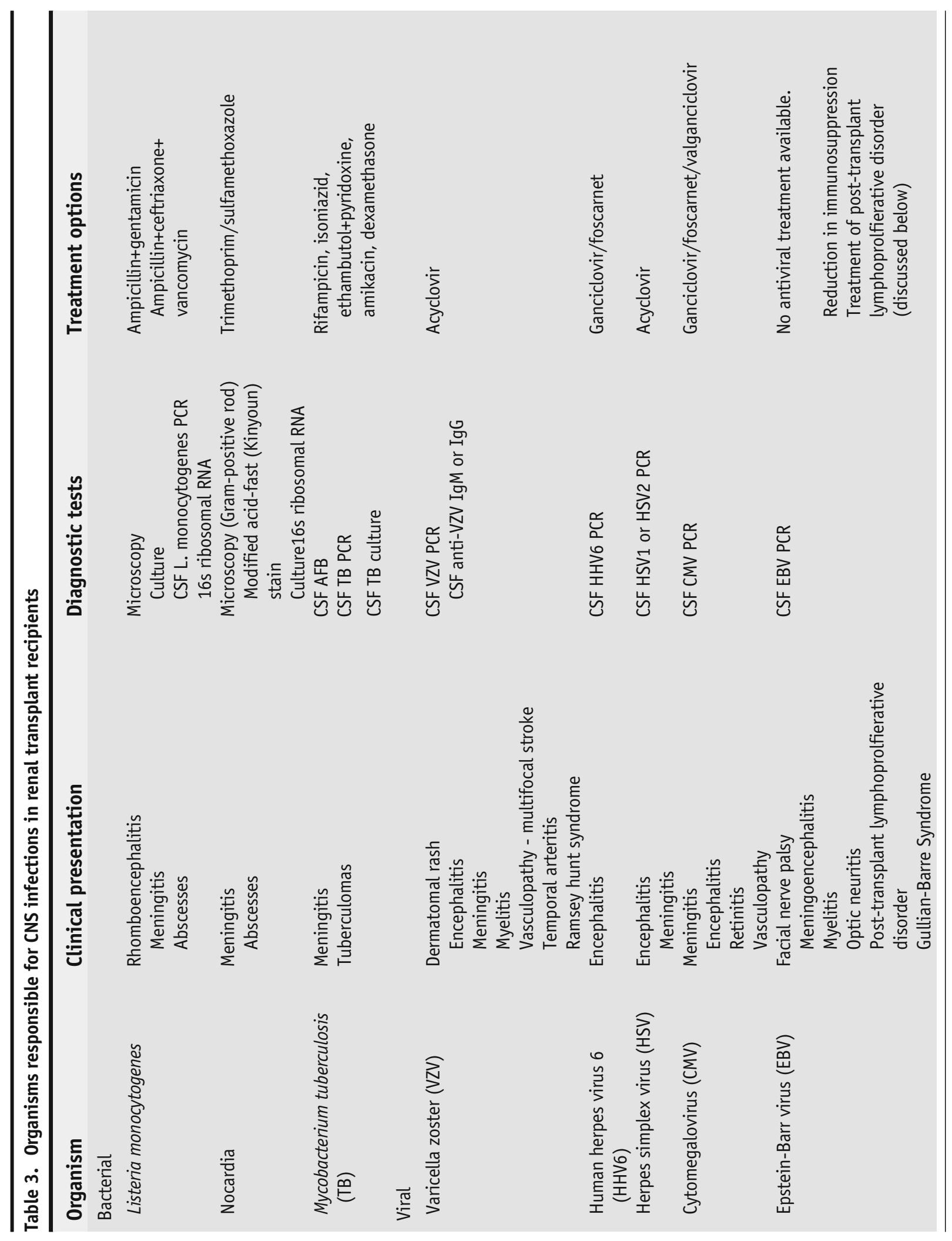



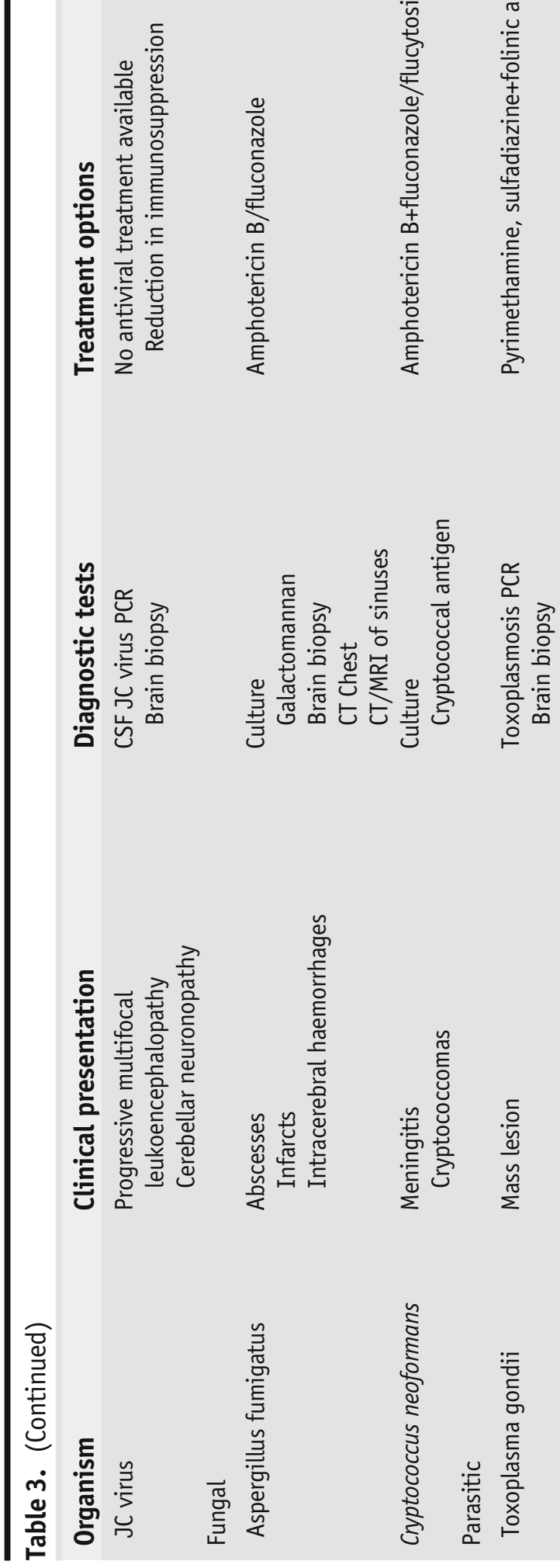


\section{Treatment of neurological complications specific to dialysis}

\section{Dialysis disequilibrium syndrome (DDS)}

This was first described in 1962 but is now rare, because of changes in dialysis regimes and increasing frequency of dialysis sessions. Cerebral oedema and raised intracranial pressure are probably the primary factors that contribute to this syndrome. It most commonly occurs during or after the first session of haemodialysis but can still occur at any stage. The initial symptoms include headache, nausea, confusion, muscle twitching and restlessness. With progression, cerebral oedema may result in seizures, coma and death [60]. Risk factors include first dialysis session, older age, severe metabolic acidosis, raised blood urea concentration predialysis $(>60 \mathrm{mmol} / \mathrm{l})$, any condition increasing blood brain permeability (such as sepsis, CNS infection or vasculitis) and pre-existing neurological disorders (e.g. stroke). Prevention should be considered in potentially high-risk patients. The most effective preventive measure is to limit the reduction of urea concentration per treatment. This can be achieved using several methods. Use of haemofiltration instead of haemodialysis reduces the rate of change of osmolalities (as solute is removed through convection rather than diffusion). If using haemodialysis, recommended methods include initiation at a relatively slower blood flow rate, and using high sodium-containing dialysates or other osmotic agents [60]. If symptoms develop during dialysis, blood flow rate should be slowed and dialysis may need to be stopped, particularly in patients who develop seizures or coma. Other differentials of the symptoms should be considered. The management is supportive with improvement usually occurring within $24 \mathrm{~h}$.

\section{Central pontine myelinolysis}

This results from rapid plasma osmotic fluctuation during haemodialysis. Risk factors include chronic hyponatraemia and elevated serum osmolality. Clinical presentation can include dysarthria, dysphagia, paraparesis, quadriparesis, confusion, movement disorders, seizures and coma. The MRI brain shows characteristic oedema in the pons and extrapontine areas. To prevent the syndrome, the serum sodium concentration should be corrected slowly, not faster than $6-8 \mathrm{mmol} / \mathrm{l}$ per day by reducing dialysate sodium or reducing the flow rate during dialysis [3].

Patients on dialysis are at increased risk due to decreased oral intake and loss of thiamine as it is water soluble. It is classically described as a triad of confusion, ataxia and ophthalmoplegia, but may involve atypical features such as neuropathy, myoclonus and chorea. Specialist renal dieticians can provide advice to improve nutritional intake to prevent the condition. Consideration of the diagnosis and rapid recognition, with initiation of thiamine replacement if it develops, is critical to minimise any long-term neurological deficits [3]. session. This probably relates to electrolyte disequilibrium effects (sodium, 
urea, magnesium, calcium), water shifts and hypotension [61]. The headache typically lasts for less than $4 \mathrm{~h}$. Diagnostic criteria according to the international headache classification system include at least three episodes of acute headache each developing during a dialysis session, worsening during dialysis and/or resolving within $72 \mathrm{~h}$ of completing dialysis. Following transplantation, the headache completely resolves [62]. There are no controlled studies of acute or prophylactic medication for use in dialysis headache treatment. ACE inhibitors, magnesium supplementation, volume maintenance, electrolyte and blood pressure control may provide some prophylactic benefit $[61 \bullet, 63]$.

\section{Treatment of neurological complications in renal transplant recipients}

Common neurological complications after renal transplant include cerebrovascular events, CNS infections, toxicity secondary to immunosuppressive medications. Rarer complications include primary CNS lymphoproliferative disease. Certain complications are more likely depending on the time elapsed after transplantation.

CNS infections in renal transplant recipients are associated with high morbidity and mortality. Early diagnosis and treatment are vital to achieve best outcome. The diagnosis can be difficult as immunosuppression may mask typical signs and symptoms. Patients can present with only headache and unexplained fever, with other features such as altered mental status, focal neurological signs, new onset seizures or meningism not being present initially. There should be a low threshold for suspecting CNS infection in renal transplant patients. All transplant patients presenting with suspected CNS infection need to be appropriately investigated (see Karunaratne et al. [3]).

Empiric treatment aimed at covering the most likely pathogens should be started early in patients with suspected CNS infection. We recommend starting ceftriaxone and aciclovir \pm ampicillin (if listeria is suspected) and early discussion with microbiology and infectious diseases teams is strongly recommended. In some cases, tapering or interrupting immunosuppressive medication may be required.

The presentation, diagnostic tests and potential therapies to be considered in the commonest CNS infections post-transplant are listed in Table 3.

The risks of infection by specific pathogens varies depending on the length of time elapsed since the transplant. This can be divided into three periods.

1. Early period post-transplant (first month). CNS infections are rare during the first month. If they occur, they are typically related to nosocomial infections (methicillin resistant Staphylococcus aureus, candida, aspergillus) or infections already present before transplantation or donor transmitted infections. 
Table 4. Neurotoxicity and mechanism of action of common immunosuppressive medication

\begin{tabular}{lcc}
\hline Drug & Mechanism of action & Neurotoxicity \\
Corticosteroids & Immunomodulating effects & $\begin{array}{c}\text { Delirium } \\
\text { Psychosis } \\
\text { Depression } \\
\text { Insomnia } \\
\text { Myopathy } \\
\text { Mycophenolate mofetil }\end{array}$ \\
& & Headache \\
& Inhibition of inosine monophosphate & \\
Calcineurin inhibitors e.g. & dehydrogenase which in turn decreases & \\
Tacrolimus and cyclosporine & guanosine. This results in inhibition of B & Tremor \\
& and T cell lymphocyte proliferation & Encephalopathy e.g. PRES \\
& Inhibition of calcineurin alters cytokines & Akinetic mutisim \\
Non calcineurin inhibitors & such IL2 and TGFB resulting in & Peripheral neurotoxicity e.g. CIDP \\
e.g. Sirolimus and everolimus & decreased activation of T lymphocytes & Tremor \\
& Inhibit mammalian target of rapamycin & Confusion \\
& (mTOR). This blocks IL2 signalling via & Paraesthesia
\end{tabular}

2. This intermediate period (from 1 to 6 months) at the peak of immunosuppression levels is a high-risk period for CNS infections such as viral infections (HSV, EBV, CMV) and opportunistic infections such as Nocardia, Toxoplasma, Listeria. Infections can precipitate organ rejection leading to increasing immunosuppressive therapy and in turn worsening control of any infective process.

3. More than 6 months after transplantation, the risk generally decreases as most patients are receiving stable reducing levels of immunosuppression. Patients who require higher than usual immunosuppressive therapy to prevent rejection are at highest risk of opportunistic infections.

\section{Neurotoxicity of immunosuppressive medication used in transplant}

Protocols for induction and maintenance of immunosuppression vary across centres. The commonest agents used in renal transplant include corticosteroids, calcineurin inhibitors, noncalcineurin inhibitors, mycophenolate and monoclonal antibodies. Neurotoxic side effects of common agents used are listed in Table 4. These may occur even within therapeutic drug levels. Reducing the dose or withdrawing and substituting the suspected offending drug with another immunosuppressive agent may be required.

Important consideration should be taken when introducing any new drugs for patients on immunosuppressive medication to minimise drugdrug interactions or the doses may need adjustment and monitoring of levels accordingly. 


\section{Post-transplant CNS lymphoproliferative disorder}

There is an increased risk of cancers and post-transplant lymphoproliferative disorders in renal transplant recipients. Risk factors include the type and intensity of immunosuppression. The majority are of B cell origin and related to EBV. Patients can present with headache, seizures, altered mental state or focal neurological deficits.

There are no RCTs and no consensus on optimal treatment of post-transplant CNS lymphoproliferative disease. Therapeutic strategies differ from immunocompetent individuals as they may include reduction in immunosuppression, antiCD20 monoclonal antibodies such as rituximab, high dose methotrexate, radiation therapy, cytotoxic chemotherapy and possibly immunotherapy [64•].

\section{Conclusion}

Both renal dialysis and transplant improve the survival of patients with chronic kidney disease and decrease the risk of neurological complications related to uraemia. Worldwide, there is an increase in the number of patients on renal replacement therapy. Early recognition and treatment of the central nervous system complications associated with RRT improves outcome and can prevent neurological disability. A collaborative approach between neurologists and renal physicians is essential for effective management of these disorders.

\section{Acknowledgments}

Dr. Malhotra is supported by the NIHR Imperial Biomedical Research Centre (BRC).

\section{Compliance with Ethical Standards}

\section{Conflict of Interest}

The authors declare that they have no conflicts of interest.

\section{Human and Animal Rights and Informed Consent}

This article does not contain any studies with human or animal subjects performed by any of the authors.

\section{Open Access}

This article is distributed under the terms of the Creative Commons Attribution 4.0 International License (http://creativecommons.org/licenses/by/4.0/), which permits unrestricted use, distribution, and reproduction in any medium, provided you give appropriate credit to the original author(s) and the source, provide a link to the Creative Commons license, and indicate if changes were made.

\section{Publisher's Note}

Springer Nature remains neutral with regard to jurisdictional claims in published maps and institutional affiliations. 


\section{References and Recommended Reading}

Papers of particular interest, published recently, have been highlighted as:

- Of importance

1. Liyanage T, Ninomiya T, Jha V, Neal B, Patrice HM, Okpechi I, et al. Worldwide access to treatment for endstage kidney disease: a systematic review. Lancet. 2015;385(9981):1975-82. https://doi.org/10.1016/ S0140-6736(14)61601-9.

2. MacNeill SJ, Ford D, Evans K, Medcalf J. Chapter 2 UK Renal Replacement Therapy Adult Prevalence in 2016: National and Centre-specific Analyses. Nephron. 2018:47-74

3. Karunaratne K, Taube D, Khalil N, Perry R, Malhotra PA. Neurological complications of renal dialysis and transplantation. Pract Neurol. 2018;18(2):115-25. https://doi.org/10.1136/practneurol-2017-001657.

4. Masson P, Webster AC, Hong M, Turner R, Lindley RI, Craig JC. Chronic kidney disease and the risk of stroke: a systematic review and meta-analysis. Nephrol Dial Transplant. 2015;30(7):1162-9. https://doi.org/10. 1093/ndt/gfv009.

5. Weigert AL, Schafer AI. Uremic bleeding: pathogenesis and therapy. Am J Med Sci. 1998;316(2):94104.

6. Kawamura M, Fijimoto S, Hisanaga S, Yamamoto Y, Eto T. Incidence, outcome, and risk factors of cerebrovascular events in patients undergoing maintenance hemodialysis. Am J Kidney Dis. 1998;31(6):991-6. https://doi.org/10.1053/ajkd.1998.v31.pm9631844.

7. Seliger SL, Gillen DL, Longstreth WT, Kestenbaum B, Stehman-Breen CO. Elevated risk of stroke among patients with end-stage renal disease. Kidney Int. 2003;64(2):603-9. https://doi.org/10.1046/j.15231755.2003.00101.x.

8.• Alqahtani F, Berzingi CO, Aljohani S, Al Hajji M, Diab $\mathrm{A}$, Alvi $\mathrm{M}$ et al. Temporal trends in the outcomes of dialysis patients admitted with acute ischemic stroke. J Am Heart Assoc. 2018;7(12). doi:https://doi.org/10. 1161/JAHA.118.008686.

Recent large-scale evaluation of outcomes of ischaemic stroke in dialysis patients.

9. Wang HH, Hung SY, Sung JM, Hung KY, Wang JD. Risk of stroke in long-term dialysis patients compared with the general population. American journal of kidney diseases : the official journal of the National Kidney Foundation. 2014;63(4):604-11. https://doi.org/10. 1053/j.ajkd.2013.10.013.

10. Power A, Chan K, Singh SK, Taube D, Duncan N Appraising stroke risk in maintenance hemodialysis patients: a large single-center cohort study. Am J Kidney Dis. 2012;59(2):249-57. https://doi.org/10.1053/j. ajkd.2011.07.016.

11. Murray AM, Seliger S, Lakshminarayan K, Herzog CA, Solid CA. Incidence of stroke before and after dialysis initiation in older patients. J Am Soc Nephrol.
2013;24(7):1166-73. https://doi.org/10.1681/ASN. 2012080841.

12. Toyoda K, Fujii K, Fujimi S, Kumai Y, Tsuchimochi $H_{\text {, }}$ Ibayashi S. Stroke in patients on maintenance hemodialysis: a 22-year single-center study. Am J Kidney Dis. 2005;45(6):1058-66. https://doi.org/10.1053/j.ajkd. 2005.02.028

13. Lentine KL, Rocca Rey LA, Kolli S, Bacchi G, Schnitzler $\mathrm{MA}$, Abbott KC, et al. Variations in the risk for cerebrovascular events after kidney transplant compared with experience on the waiting list and after graft failure. Clin J Am Soc Nephrol. 2008;3(4):1090-101. https://doi.org/10.2215/CJN.03080707.

14. Abedini S, Holme I, Fellström B, Jardine A, Cole E, Maes B, et al. Cerebrovascular events in renal transplant recipients. Transplantation. 2009;87(1):112-7. https:// doi.org/10.1097/TP.0b013e31818bfce8.

15. Willicombe M, Kumar N, Goodall D, Clarke C, McLean $\mathrm{AG}$, Power A, et al. Incidence, risk factors, and outcomes of stroke post-transplantation in patients receiving a steroid sparing immunosuppression protocol. Clin Transpl. 2015;29(1):18-25. https://doi.org/ $10.1111 /$ ctr.12476.

16. Powers WJ, Rabinstein AA, Ackerson T, Adeoye OM, Bambakidis NC, Becker K, et al. 2018 guidelines for the early management of patients with acute ischemic stroke: a guideline for healthcare professionals from the American Heart Association/American Stroke Association. Stroke. 2018;49(3):e46-e110. https://doi. org/10.1161/STR.0000000000000158.

17. Collaborative meta-analysis of randomised trials of antiplatelet therapy for prevention of death, myocardial infarction, and stroke in high risk patients. BMJ. 2002;324(7329):71-86. doi:https://doi.org/10.1136/ bmj.324.7329.71.

18. A randomised, blinded, trial of clopidogrel versus aspirin in patients at risk of ischaemic events (CAPRIE). CAPRIE Steering Committee. Lancet. 1996;348(9038):1329-39.

19. Palmer SC, Di Micco L, Razavian M, Craig JC, Perkovic $\mathrm{V}$, Pellegrini F et al. Antiplatelet agents for chronic kidney disease. Cochrane Database Syst Rev 2013(4). doi:https://doi.org/10.1002/14651858.CD008834. pub3.

20. Ethier J, Bragg-Gresham JL, Piera L, Akizawa T, Asano Y, Mason N, et al. Aspirin prescription and outcomes in hemodialysis patients: the Dialysis Outcomes and Practice Patterns Study (DOPPS). Am J Kidney Dis: the official journal of the National Kidney Foundation. 2007;50(4):602-11. https://doi.org/10.1053/j.ajkd. 2007.07.007.

21. Potpara TS, Ferro CJ, Lip GYH. Use of oral anticoagulants in patients with atrial fibrillation and renal 
dysfunction. Nat Rev Nephrol. 2018;14(5):337-51. https://doi.org/10.1038/nrneph.2018.19.

22.• Steffel J, Verhamme P, Potpara TS, Albaladejo P, Antz M, Desteghe L, et al. The 2018 European Heart Rhythm Association Practical Guide on the use of non-vitamin $\mathrm{K}$ antagonist oral anticoagulants in patients with atrial fibrillation. Eur Heart J. 2018;39(16):1330-93. https:// doi.org/10.1093/eurheartj/ehy136.

Recent review of anticogaulation in atrial fibrilation including a specific section on use in dialysis patients.

23. Fox KA, Piccini JP, Wojdyla D, Becker RC, Halperin JL, Nessel CC, et al. Prevention of stroke and systemic embolism with rivaroxaban compared with warfarin in patients with non-valvular atrial fibrillation and moderate renal impairment. Eur Heart J.

2011;32(19):2387-94. https://doi.org/10.1093/ eurheartj/ehr342.

24. Hohnloser SH, Hijazi Z, Thomas L, Alexander JH, Amerena J, Hanna M, et al. Efficacy of apixaban when compared with warfarin in relation to renal function in patients with atrial fibrillation: insights from the ARISTOTLE trial. Eur Heart J. 2012;33(22):2821-30. https://doi.org/10.1093/ eurheartj/ehs274.

25. Hijazi Z, Hohnloser SH, Oldgren J, Andersson U, Connolly SJ, Eikelboom JW, et al. Efficacy and safety of dabigatran compared with warfarin in relation to baseline renal function in patients with atrial fibrillation: a RE-LY (Randomized Evaluation of Long-term Anticoagulation Therapy) trial analysis. Circulation. 2014;129(9):961-70. https://doi.org/10.1161/ circulationaha.113.003628.

26. Shah M, Avgil Tsadok M, Jackevicius CA, Essebag V, Eisenberg MJ, Rahme E, et al. Warfarin use and the risk for stroke and bleeding in patients with atrial fibrillation undergoing dialysis. Circulation.

2014;129(11):1196-203. https://doi.org/10.1161/ CIRCULATIONAHA.113.004777.

27. Baigent C, Landray MJ, Reith C, Emberson J, Wheeler DC, Tomson C, et al. The effects of lowering LDL cholesterol with simvastatin plus ezetimibe in patients with chronic kidney disease (Study of Heart and Renal Protection): a randomised placebo-controlled trial. Lancet. 2011;377(9784):2181-92. https://doi.org/10. 1016/s0140-6736(11)60739-3.

28. Green D, Ritchie JP, Kalra PA. Meta-analysis of lipidlowering therapy in maintenance dialysis patients. Nephron Clin Pract. 2013;124(3-4):209-17. https:// doi.org/10.1159/000357676.

29. Marz W, Genser B, Drechsler C, Krane V, Grammer TB, Ritz E, et al. Atorvastatin and low-density lipoprotein cholesterol in type 2 diabetes mellitus patients on hemodialysis. Clin J Am Soc Nephrol. 2011;6(6):131625. https://doi.org/10.2215/cjn.09121010.

30. Holdaas H, Holme I, Schmieder RE, Jardine AG, Zannad F, Norby GE, et al. Rosuvastatin in diabetic hemodialysis patients. J Am Soc Nephrol. 2011;22(7):1335-41. https://doi.org/10.1681/asn. 2010090987.
31. Wanner C, Krane V, Marz W, Olschewski M, Mann JF, Ruf $\mathrm{G}$, et al. Atorvastatin in patients with type 2 diabetes mellitus undergoing hemodialysis. N Engl J Med. 2005;353(3):238-48. https://doi.org/10.1056/ NEJMoa043545.

32. Wanner $\mathrm{C}$, Tonelli M, the Kidney Disease: Improving Global Outcomes Lipid Guideline Development Work Group M. KDIGO Clinical Practice Guideline for Lipid Management in CKD: summary of recommendation statements and clinical approach to the patient. Kidney Int. 2014;85(6):1303-9. https://doi.org/10.1038/ki. 2014.31.

33. Holdaas H, Fellstrom B, Jardine AG, Holme I, Nyberg G, Fauchald P, et al. Effect of fluvastatin on cardiac outcomes in renal transplant recipients: a multicentre, randomised, placebo-controlled trial. Lancet. 2003;361(9374):2024-31. https://doi.org/10.1016/ s0140-6736(03)13638-0.

34. Rashid P, Leonardi-Bee J, Bath P. Blood pressure reduction and secondary prevention of stroke and other vascular events: a systematic review. Stroke. 2003;34(11):2741-8. https://doi.org/10.1161/01.str. 0000092488.40085 .15 .

35. Herrington W, Haynes R, Staplin N, Emberson J, Baigent $\mathrm{C}$, Landray M. Evidence for the prevention and treatment of stroke in dialysis patients. Semin Dial. 2015;28(1):3547. https://doi.org/10.1111/sdi.12281.

36. Agarwal R, Sinha AD. Cardiovascular protection with antihypertensive drugs in dialysis patients: systematic review and meta-analysis. Hypertension. 2009;53(5):860-6. https://doi.org/10.1161/ hypertensionaha.108.128116.

37. Heerspink HJ, Ninomiya T, Zoungas S, de Zeeuw D, Grobbee DE, Jardine MJ, et al. Effect of lowering blood pressure on cardiovascular events and mortality in patients on dialysis: a systematic review and metaanalysis of randomised controlled trials. Lancet. 2009;373(9668):1009-15. https://doi.org/10.1016/ s0140-6736(09)60212-9.

38. Wheeler DC, Becker GJ. Summary of KDIGO guideline. What do we really know about management of blood pressure in patients with chronic kidney disease? Kidney Int. 2013;83(3):377-83. https://doi.org/10.1038/ ki.2012.425.

39. Lees KR, Bluhmki E, von Kummer R, Brott TG, Toni D, Grotta JC et al. Time to treatment with intravenous alteplase and outcome in stroke: an updated pooled analysis of ECASS, ATLANTIS, NINDS, and EPITHET trials. Lancet (London, England). 2010;375(9727):1695-703. doi:https://doi.org/10. 1016/s0140-6736(10)60491-6.

40. Sandercock P, Wardlaw JM, Lindley RI, Dennis M, Cohen G, Murray G, et al. The benefits and harms of intravenous thrombolysis with recombinant tissue plasminogen activator within $6 \mathrm{~h}$ of acute ischaemic stroke (the third international stroke trial [IST-3]): a randomised controlled trial. Lancet. 2012;379(9834):2352-63. https://doi.org/10.1016/ s0140-6736(12)60768-5. 
41.• Carr SJ, Wang X, Olavarria VV, Lavados PM, Rodriguez JA, Kim JS, et al. Influence of renal impairment on outcome for thrombolysis-treated acute ischemic stroke: ENCHANTED (Enhanced Control of Hypertension and Thrombolysis Stroke Study) post hoc analysis. Stroke. 2017;48(9):2605-9. https://doi.org/ 10.1161/STROKEAHA.117.017808

The only post-hoc analysis of a randomised trial of stroke thrombolysis in renal dysfunction.

42. Naganuma $M$, Koga $M$, Shiokawa $Y$, Nakagawara J, Furui E, Kimura K, et al. Reduced estimated glomerular filtration rate is associated with stroke outcome after intravenous rt-PA: the Stroke Acute Management with Urgent Risk-Factor Assessment and Improvement (SAMURAI) rt-PA registry. Cerebrovasc Dis. 2011;31(2):123-9. https://doi. org/10.1159/000321516.

43. Gensicke H, Zinkstok SM, Roos YB, Seiffge DJ, Ringleb $\mathrm{P}$, Artto $\mathrm{V}$, et al. IV thrombolysis and renal function. Neurology. 2013;81(20):1780-8. https://doi.org/10. 1212/01.wnl.0000435550.83200.9e.

44. Tariq N, Adil MM, Saeed F, Chaudhry SA, Qureshi AI. Outcomes of thrombolytic treatment for acute ischemic stroke in dialysis-dependent patients in the United States. J Stroke Cerebrovasc Dis. 2013;22(8):e354-9. https://doi. org/10.1016/j.jstrokecerebrovasdis.2013.03.016

45. Jovin TG, Chamorro A, Cobo E, de Miquel MA, Molina CA, Rovira A, et al. Thrombectomy within 8 hours after symptom onset in ischemic stroke. $\mathrm{N}$ Engl J Med. 2015;372(24):2296-306. https://doi.org/10.1056/ NEJMoa1503780.

46. Saver JL, Goyal M, Bonafe A, Diener H-C, Levy EI, Pereira VM, et al. Stent-retriever thrombectomy after intravenous t-PA vs. t-PA alone in stroke. N Engl J Med. 2015;372(24):2285-95. https://doi.org/10.1056/ NEJMoa1415061.

47. Campbell BCV, Mitchell PJ, Kleinig TJ, Dewey HM, Churilov L, Yassi N, et al. Endovascular therapy for ischemic stroke with perfusion-imaging selection. $\mathrm{N}$ Engl J Med. 2015;372(11):1009-18. https://doi.org/ 10.1056/NEJMoa1414792.

48. Goyal M, Demchuk AM, Menon BK, Eesa M, Rempel JL, Thornton J, et al. Randomized assessment of rapid endovascular treatment of ischemic stroke. N Engl J Med. 2015;372(11):1019-30. https://doi.org/10. 1056/NEJMoa1414905.

49. Saeed F, Adil MM, Piracha BH, Qureshi AI. Outcomes of endovascular versus intravenous thrombolytic treatment for acute ischemic stroke in dialysis patients. Int J Artif Organs. 2014;37(10):727-33. https://doi. org/10.5301/ijao.5000349.

50. Dastur CK, Yu W. Current management of spontaneous intracerebral haemorrhage. Stroke Vasc Neurol. 2017. doi:https://doi.org/10.1136/svn-2016-000047.

51. Power A, Hamady M, Singh S, Ashby D, Taube D, Duncan N. High but stable incidence of subdural haematoma in haemodialysis-a single-centre study. Nephrol Dial Transplant. 2010;25(7):2272-5. https:// doi.org/10.1093/ndt/gfq013.
52. Janssen MJ, van der Meulen J. The bleeding risk in chronic haemodialysis: preventive strategies in highrisk patients. Neth J Med. 1996;48(5):198-207.

53. Fugate JE, Rabinstein AA. Posterior reversible encephalopathy syndrome: clinical and radiological manifestations, pathophysiology, and outstanding questions. Lancet Neurol. 2015;14(9):914-25. https://doi.org/10. 1016/s1474-4422(15)00111-8

This paper provides a thorough review of posterior reversible encephalopathy.

54. Neligan A. Oxford Textbook of Epilepsy and Epileptic Seizures. Epilepsy in Renal, Hepatic, and Other Conditions. 2012.

55. Bansal AD, Hill CE, Berns JS. Use of antiepileptic drugs in patients with chronic kidney disease and end stage renal disease. Semin Dial. 2015;28(4):404-12. https:// doi.org/10.1111/sdi.12385.

56. Asconape JJ. Use of antiepileptic drugs in hepatic and renal disease. Handb Clin Neurol. 2014;119:417-32. https://doi.org/10.1016/b978-0-7020-4086-3.00027-8.

57. Anderson GD, Hakimian S. Pharmacokinetic of antiepileptic drugs in patients with hepatic or renal impairment. Clin Pharmacokinet. 2014;53(1):29-49. https://doi.org/10.1007/s40262-013-0107-0.

58. Israni RK, Kasbekar N, Haynes K, Berns JS. Use of antiepileptic drugs in patients with kidney disease. Semin Dial. 2006;19(5):408-16. https://doi.org/10. 1111/j.1525-139X.2006.00195.x.

59. Marvanova M. Pharmacokinetic characteristics of antiepileptic drugs (AEDs). Mental Health Clinician. 2016;6(1):8-20. https://doi.org/10.9740/mhc.2015. 01.008 .

60. Zepeda-Orozco D, Quigley R. Dialysis disequilibrium syndrome. Pediatr Nephrol. 2012;27(12):2205-11. https://doi.org/10.1007/s00467-012-2199-4.

61. Sousa Melo E, Carrilho Aguiar F, Sampaio Rocha-Filho PA. Dialysis headache: a narrative review. Headache. 2017;57(1):161-4. https://doi.org/10.1111/head. 12875

General review of dialysis headache which is under-recognised complication of dialysis.

62. The International Classification of Headache Disorders, 3rd edition (beta version). Cephalalgia 2013;33(9):629-808. doi:https://doi.org/10.1177/ 0333102413485658.

63. Leinisch-Dahlke E, Schmidt-Wilcke T, Kramer BK, May A. Improvement of dialysis headache after treatment with ACE-inhibitors but not angiotensin II receptor blocker: a case report with pathophysiological considerations. Cephalalgia. 2005;25(1):71-4. https://doi. org/10.1111/j.1468-2982.2004.00804.x.

64. Dierickx D, Habermann TM. Post-Transplantation Lymphoproliferative Disorders in Adults. N Engl J Med. 2018;378(6):549-62. https://doi.org/10.1056/ NEJMra 1702693

This paper gives a general overview of this important topic including solid organ transplant patients. 